\title{
Clinical Evaluation of Residual Ridge Morphology of Maxillary Arch in Relation to Ageing and Length of Edentulism
}

\author{
Rinu Sharma, ${ }^{1}$ Amar Bhochhibhoya, ${ }^{1}$ BinodAcharya, ${ }^{1}$ Samskar Bickram Rana ${ }^{1}$ \\ ${ }^{1}$ Department of Prosthodontics, College of Dental Sciences and Hospital Nepal Medical College, Attarkhel, Jorpati, \\ Kathmandu, Nepal.
}

\begin{abstract}
Background: Ridge morphology is one of the important recognized factors affecting denture retention, stability, support and masticatory function in edentulous patients. The form of ridge affects the planning as well as determines the prognosis of treatment. The objective of this study was to assess maxillary residual ridge morphology according to American College of Prosthodontists (ACP) classification system and to find association between type of ridge morphology of maxillary arch with age and duration of edentulism. Methods: The study was conducted among 87 completely edentulous patients above 40 years of age visiting department of prosthodontics Nepal Medical College. The morphology of maxillary residual ridges were clinically evaluated and classified according to criteria given by American College of Prosthodontists (ACP) classification system. The findings were associated with age, sex, duration of edentulism and complete denture wear. Results: In this study, more than two thirds of the patients belonged to the age group of 60 80 years and their mean duration of edentulousness was seen to be 5.7 years. One fifth of the patients were using previous complete dentures. Type A maxillary ridge morphology was found to be the most prevalent. The type of maxillary ridge morphology was not found to be associated with either age or gender of an individual however it varied significantly with length of edentulism and duration of complete denture wears. Conclusions: Within limitations, it can be concluded that maxillary ridge morphology was not associated with age of an individual however the longer duration of edentulism or complete denture use would make the type of ridge morphology more unfavorable.
\end{abstract}

Keywords: maxillary ridge; length of edentulism; residual ridge resorption; ridge morphology.

\section{INTRODUCTION}

The morphology of residual alveolar ridge influences different phases of treatment in prosthetic dentistry. It is important to know the quality as well as quantity of available bone before treatment planning as the type of residual ridge determines the available support for removable partial and complete dentures. The loss of bone in residual alveolar ridge varies not only from patient to patient but also from one region to the other. The continued decrease in bone volume affects: denture-bearing area; tissues remaining for reconstruction; facial muscle support/attachment; total facial height; and ridge morphology. ${ }^{1}$ Ridge morphology being one of the important recognized factors affecting denture retention, stability, support and masticatory function in edentulous patients. ${ }^{2}$

Various authors have attempted to classify residual ridge morphology including Atwood et al.who have concluded that the reduction of the residual ridge leads to a variety of stages of ridge form. ${ }^{3}$ American College of Prosthodontists (ACP) developed a classification system which was published by McGarry et al. in 1999, wherein they have clinically classified maxillary ridge morphology into Type $\mathrm{A}, \mathrm{B}, \mathrm{C}$ and $\mathrm{D}$ as diagnostic entity helpful in predicting complexity of treatment. ${ }^{4}$ This classification system of maxillary ridge morphology can be utilized to assess various levels of ridge resorption in maxilla and determine whether it is apt to be successfully treated by conventional prosthodontic techniques. It is clinically convenient classification and also describes the effects of ridge morphology and influence of musculature on a maxillary denture. ${ }^{4}$

In this study, we have clinically evaluated the ridge morphology of maxillary arch as described by ACP classification system and studied whether the morphology of ridge type varies with age, length of edentulism and duration of complete denture wear.

\section{METHODS}

87 completely edentulous patients visiting Department of Prosthodontics from April to August 2019, Nepal Medical College and who meet inclusion criteria were selected for this study.

Correspondence: Dr. Rinu Sharma, Lecturer, Department of Prosthodontics, College of Dental Sciences and Hospital, Nepal Medical College, Attarkhel, Jorpati, Kathmandu, Nepal. Email: dr.sharmarinu@gmail.com. Phone: +9779851117185. Article received: 2019-9-29. Article accepted: 2019-12-10. 
General information including age, gender, length of edentulism and duration of complete denture wear were recorded for all patients. The patients enrolled were above 40 years with completely healed maxillary residual alveolar ridge. Among selected patients, clinical evaluation of the maxillary residual ridge morphology was performed and ridge morphology was classified into four types according to criteria given by American College of Prosthodontists (ACP) in $1999^{4}$ as:

Type A - Palatal morphology, anterior labial and posterior buccal vestibular depth as well as tuberosity that resists vertical and horizontal movement of the denture base, well defined hamular notch to establish the posterior extension of the denture base, absence of tori or exostoses.

Type B - Loss of posterior buccal vestibule, palatal vault morphology resists vertical and horizontal movement of the denture base, tuberosity and hamular notch are poorly defined compromising delineation of the posterior extension of the denture base, maxillary palatal tori and/or lateral exostoses are rounded and do not affect the posterior extension of the denture base.

Type C - Loss of anterior labial vestibule, palatal vault morphology offers minimal resistance to vertical and horizontal movement of the denture base. Maxillary palatal tori and/or lateral exostoses with bony undercuts that do not affect the posterior extension of the denture base, hyperplastic mobile anterior ridge that offers minimum support and stability of the denture base, reduction of the post-malar space by the coronoid process during mandibular opening and/or excursive movements. Type D - Loss of anterior labial and posterior buccal vestibules, palatal vault morphology does not resist vertical or horizontal movement of the denture base. Maxillary palatal tori and/or lateral exostoses (rounded or undercut) that interfere with the posterior border of the denture, hyperplastic redundant anterior ridge, prominent anterior nasal spine.

According to the above-mentioned criteria, residual ridge morphology of maxillary arch were evaluated and classified. The recorded data were entered, coded and analyzed using SPSS version 17 . The associations of ACP classified ridges with age group and duration of edentulism were tested with the help of Chi-Squared tests and Fisher Exact test depending on the distribution. The level of significance was set at 5\%.

\section{RESULTS}

In this study, more than two thirds of the patients belonged to the age group of 60-80 years while the average age of the patients was 65 years with maximum being 86 and minimum being 48 years. More than half $(51.7 \%)$ of the patients involved in this study were females. Co-morbid health conditions were present in a quarter $(25.3 \%)$ of patients with hypertension being the most common condition (Table 1). The mean duration of

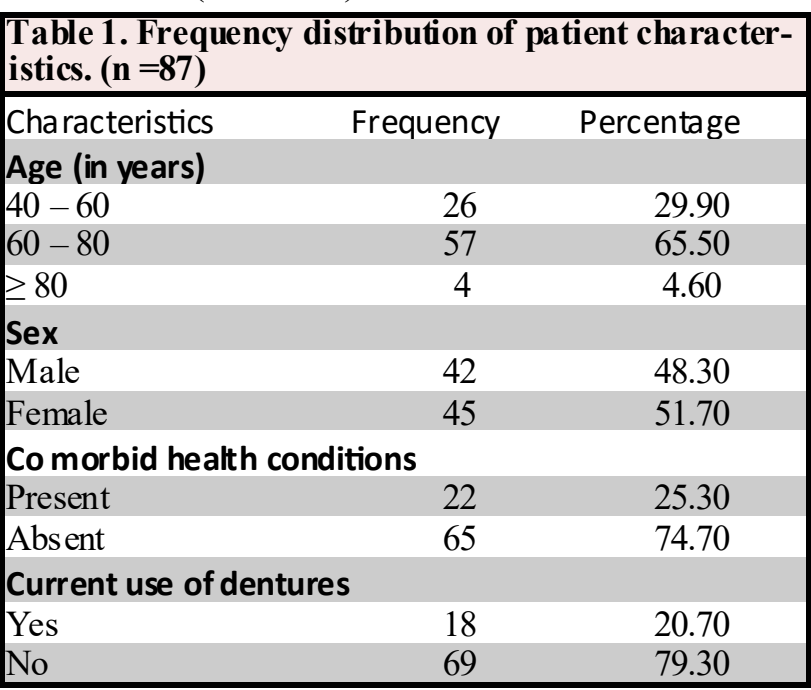

edentulousness was seen to be 5.7 years and among them about one fifth of the patients were previous complete denture wearers. The mean duration of denture use was 4.9 years while the maximum use was found to be for 22 years (Table 2).

\begin{tabular}{|c|c|c|}
\hline Variables (In years) & Mean \pm SD & $\begin{array}{l}\text { Minimum - } \\
\text { Maximum }\end{array}$ \\
\hline Age of patients & $65.37 \pm 8.60$ & $48-86$ \\
\hline Duration of edentulo usness & $5.76 \pm 6.45$ & $0.2-30$ \\
\hline $\begin{array}{l}\text { Duration of denture use (n } \\
=18 \text { ) }\end{array}$ & $4.9 \pm 5.71$ & $0.1-22$ \\
\hline
\end{tabular}

The majority ( $46 \%$ ) of the study patients had Type A maxillary ridge morphology followed by Type $\mathrm{B}$ $(41.4 \%)$ and Type C (12.6\%). However none of the patients showed type D ridge morphology in this study (Figure 1).

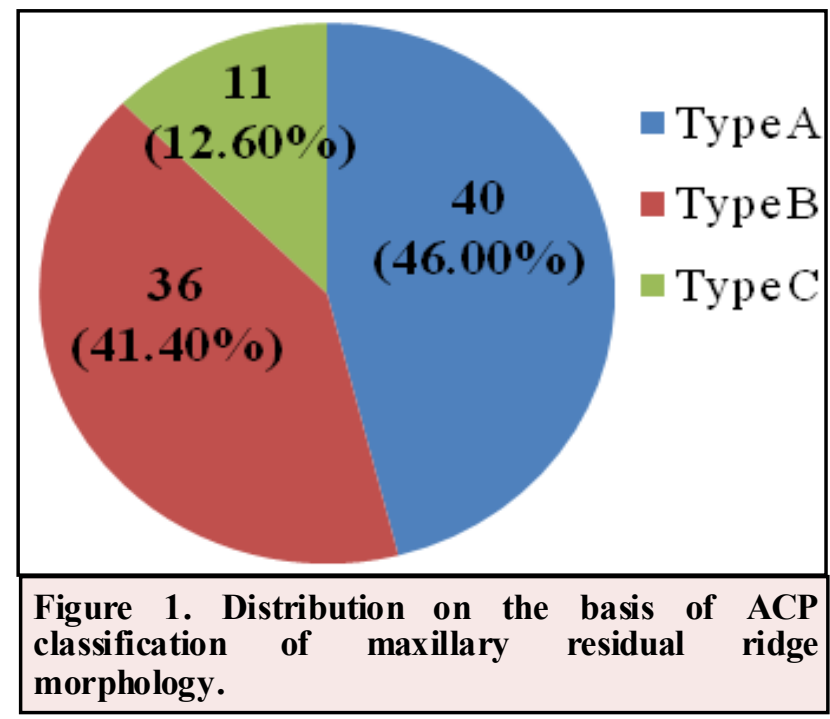

The mean age of study patients in all three types of ridge morphology was around 65 years. Thus, there was no significant difference observed in age of patients belonging to either type A, B and C. On 
the other hand, duration of edentulousness was significantly associated $(\mathrm{p}=0.04)$ with type of maxillary ridge morphology. In this study, we found that mean duration of edentulousness was significantly higher among patients with Type C morphology compared to type A and type B. No significant difference was however observed between type A and type B (Table 3).

\begin{tabular}{|c|c|c|c|c|}
\hline $\begin{array}{l}\text { Table 3. } \\
\text { edentulousn } \\
\text { morphology }\end{array}$ & $\begin{array}{ll}\text { Association of age } & \text { of } \\
\text { ess with maxilla } \\
\end{array}$ & $\begin{array}{l}\text { e and d } \\
\text { iry resid }\end{array}$ & $\begin{array}{l}\text { duratio } \\
\text { dual }\end{array}$ & \begin{tabular}{rr|} 
r & of \\
ridge
\end{tabular} \\
\hline & Maxillary ridge mo & orphology & & \\
\hline variables & $\begin{array}{cc}\text { Type A } & \text { Type B } \\
(\text { mean } \pm & (\text { mean } \pm \\
\text { sd }) & \text { sd })\end{array}$ & $\begin{array}{l}\text { Type C } \\
\text { (mean } \pm \\
\text { sd) }\end{array}$ & $\begin{array}{l}\text { F } \\
\text { sta- } \\
\text { tistic }\end{array}$ & $\begin{array}{c}P \\
\text { value }\end{array}$ \\
\hline Age & $\begin{array}{ll}64.68 & 65.69 \\
\pm 9.75 & \pm 7.30\end{array}$ & $\begin{array}{l}66.82 \\
\pm 8.61\end{array}$ & 0.3 & 0.8 \\
\hline $\begin{array}{l}\text { Duration of } \\
\text { edentulous- } \\
\text { ness }\end{array}$ & $\begin{array}{l}4.81 \pm \\
5.15^{*}\end{array}$ & $\begin{array}{l}10.29 \pm \\
8.87^{* \#}\end{array}$ & 3.35 & 0.04 \\
\hline
\end{tabular}

Result shows that majority of the male patients had type A morphology followed by Type B and Type C. Similar findings were observed among the female patients as well. Thus, the difference in proportion failed to reach statistical significance highlighting no association of sex with maxillary ridge morphology among edentulous patients. On the other hand, Type A ridge morphology was most common among the denture wearers while Type B was most common among the non-denture wearers. This finding was statistically significant with $\mathrm{p}$ value 0.047 (Table 4).

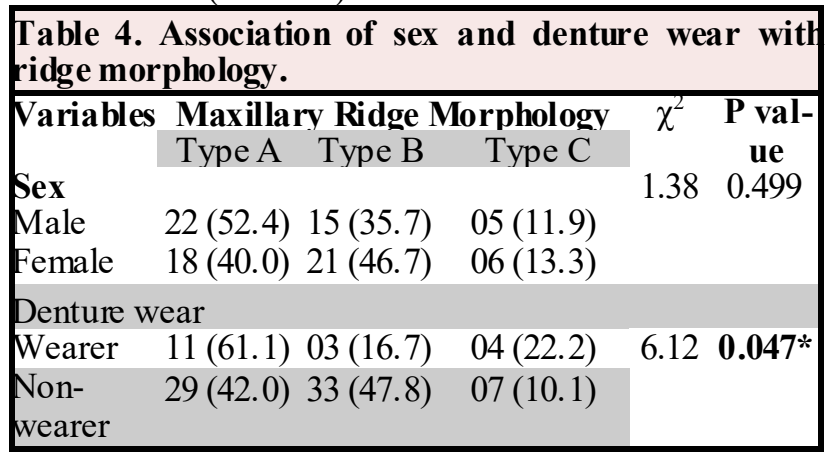

\section{DISCUSSION}

The morphology of residual ridge changes with the amount of bone loss which is usually greater during the first few months after tooth extraction than later. ${ }^{5}$ In a follow-up study of edentulous patients over an average of 2.5 years, Atwood and Coy found a mean annual bone loss of $0.1 \mathrm{~mm}$ in the maxilla. ${ }^{6}$ However, Tallgren et al. documented a slightly lower amount of $0.05 \mathrm{~mm}$ over 25 years. ${ }^{7}$ Ridge resorption in the edentulous jaw is however a continuous process that may proceed throughout the lifetime of a denture wearer and it directly affects the morphology of ridges. In this study, maxillary ridge morphology was clinically evaluated since the assessment of maxillary residual ridge by radiographic method is not found very reliable and the radiographic assessment also does not seem practical for all patients. ${ }^{8}$ The majority of our study participants had Type A maxillary ridge morphology followed by Type B and $\mathrm{C}$. However none of the patients showed type $\mathrm{D}$ ridge morphology. Type $\mathrm{D}$ relates to highly compromised ridge form with loss of vestibular depth and presence of tori or hyperplastic tissues. On a comparative study of maxillary denture bases, Alhelal et al. also found majority of their participants had Type A ridge morphology while non among them showed Type D. ${ }^{9}$

Bone formation is greater than bone resorption in growing individuals but when a person ages, the resorption may not be compensated by production of bone resulting in senile osteoporosis. With increasing age, there is also a reduced capacity of osteoblasts to proliferate and differentiate in response to hormones or growth factors. ${ }^{5}$ Venkatesan $\mathrm{N}$ et al., found increase in rate of resorption with increasing age and comparing between the genders, the resorption rate was found more in females than males. ${ }^{10}$ The reduction on the height of edentulous mandible and maxilla was found more pronounced in women than in men. ${ }^{11}$ Other studies also found higher resorption in females than in men. ${ }^{10,12,13} \mathrm{~A}$ study conducted only on male participants to overcome variables associated with osteoporosis and menopause in women, concluded that ridge height reduction was linear throughout the ages. ${ }^{14}$ In this study, age of participants ranged from 48 to 86 years with majority of females, but interestingly, there was no correlation of either age or gender with the type of ridge morphology. Some other studies similarly showed, the amount of alveolar bone resorption was not correlated with the age of the subjects. ${ }^{15,16}$ However, type of ridge was significantly associated with duration of edentulism in this study. With increase in duration, the ridge type changed from type $\mathrm{A}$ to $\mathrm{B}$ and with longer duration of edentulism Type $\mathrm{C}$ was found to be most common.

Literatures have shown mixed results regarding various factors associated with ridge loss. In a study done on mandibular arch, the degree of alveolar bone resorption and the duration of complete dentures wear is found to be correlated. ${ }^{12}$ This implies that the mandibular ridges of people who have been edentulous for longer periods are more extensively resorbed. In contrast, some studies, conducted in early post-menopausal women, failed to find such an association. ${ }^{17} \mathrm{~A}$ cross-sectional study by Taguchi et al. in Japanese elderly women, found that patients with long period of edentulousness loose greater amount of bone than those with short period of edentulousness. ${ }^{18}$ The 
rate of ridge resorption, according to Karaagaclioglu et al. was greatest in the earlier stages of edentulism and slowed with length of edentulism. ${ }^{19}$ The type of ridge morphology was also associated with complete denture wear in our study, with denture wearers having more favorable type A or B ridges than non-wearers. In contrast, Al -Jabrah et al. found ridge resorption on mandibular arch increased with increasing age and duration of denture wear. ${ }^{12}$ Unger et al. evaluated the height of ridges in denture wearers from initial insertion of complete denture to 20 years after placement and found no correlation of bone height and ridge loss on both maxillary and mandibular arches. ${ }^{20}$

\section{CONCLUSIONS}

Within the limitations of study, it can be concluded that ACP classification Type A maxillary ridge morphology is most prevalent and Type D is the least prevalent in our population. The Type of ACP classified ridge is not associated with either age or gender of an individual however it varied significantly with length of edentulism and duration of complete denture wear.

\section{REFERENCES}

1. McGarry TJ, Nimmo A, Skiba JF, Ahlstrom RH, Smith CR and Koumjian JH. Classification system for partial edentulism. J Prosthodont. 2002; 11: 181-93.https://doi.org/10.1053/ jopr.2002.126094

2. Wyatt CC. The effect of prosthodontic treatment on alveolar bone loss: a review of the literature. J Prosthet Dent.1998; 80: 3626.https://doi.org/10.1016/S0022-3913(98)70138 $-6$

3. AtwoodDA. Postextraction changes in the adult mandible as illustrated by microradiographs of midsagittal sections and serial cephalometric roentgenograms. J Prosthet Dent. 1963; 13: 810 -24.https://doi. org/10.1016/0022-3913(63) 90225-7

4. McGarry TJ, Nimmo A, Skiba JF, Ahlstrom RH, Smith CR and Koumjian JH. Classification system for complete edentulism. J Prosthodont. 1999; 8: 27-39.https://www.ncbi.nlm.nih.gov/ pubmed/11665423

5. Heersche JN, Bellows CG and Ishida Y. The decrease in bone mass associated with aging and menopause. J Prosthet Dent. 1998; 79: 14 6.https://doi.org/10.1016/S0022-3913(98)70187 $-8$

6. Atwood DA and Coy WA. Clinical, cephalometric, and densitometric study of reduction of residual ridges. J Prosthet Dent. 1971; 26: 280-95.https://doi.org/10.1016/00223913(71)90070-9

7. Tallgren A. The continuing reduction of the residual alveolar ridges in complete denture wearers: a mixed-longitudinal study covering 25 years. J Prosthet Dent. 1972; 27: 12032.https://doi.org/10.1016/0022-3913(72)90188 $-6$

8. Davis D. Developing an analogue/substitute for the maxillary denture-bearing area in Zarb GA, Bolender CL, Carlsson GE, (Ed.), Boucher's Prosthodontic Treatment for Edentulous Patients. $11^{\text {th }}$ ed. St Louis: Mosby. 1997: 14161.

9. AlHelal A, AlRumaih HS, Kattadiyil MT, Baba NZ and Goodacre CJ. Comparison of retention between maxillary milled and conventional denture bases: a clinical study. J Prosthet Dent. 2017; 117: 233-8.https://doi.org/10.1016/ j.prosdent.2016.08.007

10. Venkatesan N KVC, Thenmozhi N, Udhayan A, Raghunathan J. Analysing the residual ridge morphology and resorption for treatment of edentulous patient with complete denture in Melmaruvathur population. Int. J Rec Sci Res. 2018; 9: 25529-32.http://dx.doi.org/10.24327/ ijrsr.2018.0904.1876

11. Abdulhadi LM and Kasiapan S. Residual alveolar ridge resorption in completely edentulous patients influenced by pathophysiologic factors. Dentika Dent J. 2009; 14.

12. Al-Jabrah O and Al-Shumailan Y. Association of complete denture wearing with the rate of reduction of mandibular residual ridge using digital panoramic radiography. Int J Dent Res. 2014; 2: 20-5.https://doi.org/10.14419/ ijdr.v2i1.1669

13. Ural Ç, Bereket C, Sener Ý, Aktan AM and Akpinar YZ. Bone height measurement of maxillary and mandibular bones in panoramic radiographs of edentulous patients. J Clin Exp Dent. 2011; 3(1):e5-9.http:// www.medicinaoral.com/odo/volumenes/v3i1/ jcedv3i1p5.pdf

14. Jagadeesh MS, Patil RA and Kattimani PT. Clinical evaluation of mandibular ridge height in relation to aging and length of edentulism. IOSR J Dent Med Sci. 2013; 3: 44-7.

15. Saglam AA. The vertical heights of maxillary and mandibular bones in panoramic radiographs of dentate and edentulous subjects. Quintessence Int. 2002Jun; 33(6):433-8.

16. Neha Vaidya AG, BC Muddugangadhar, Poonam RaoT, Vishal Seth. Radiomorphometric indices and their relation to alveolar bone loss in completely edentulous patients: A prospective study. Int J Adv Res. 2016; 5: 118-34.

17. Kribbs PJ. Comparison of mandibular bone in normal and osteoporotic women. J Prosthet Dent. 1990; 63: 218-22. https:// doi.org/10.1016/0022-3913(90)90108-o

18. Taguchi A, Suei Y, Ohtsuka M, Otani K, 
Tanimoto K and Hollender L. Relationship between bone mineral density and tooth loss in elderly Japanese women. Dent Maxillofac Radiol. $\quad 1999 ; \quad 28$ : 219-23.https:// doi.org/10.1038/sj/dmfr/4600445

19. Karaagaçlioglu L and Ozkan P. Changes in mandibular ridge height in relation to aging and length of edentulism period. Int J Prosthodont. 1994 Jul-Aug; 7(4): 368-71.

20. Unger JW, Ellinger CW and Gunsolley JC. An analysis of the effect of mandibular length on residual ridge loss in the edentulous patient.J Prosthet Dent. 1992; 67: 827-30.https:// doi.org/10.1016/0022-3913(92)90593-y

Citation: Sharma R, Bhochhibhoya A, Acharya B, Rana SB. Clinical Evaluation of Residual Ridge Morphology of Maxillary Arch in Relation to Ageing and Length of Edentulism. JCMS Nepal. 2019; 15 (4):230-4. 